\title{
Lipoprotein(a) and Its Position among Other Risk Factors of Atherosclerosis
}

\author{
L. ZLATOHLÁVEK ${ }^{1}$, K. ZÍDKOVÁ ${ }^{1}$, M. VRABLÍK ${ }^{1}$, T. HAAS ${ }^{2}$, M. PRUSÍKOVÁ ${ }^{1}$, \\ H. SVOBODOVÁ ${ }^{1}$, R. ČEŠKA ${ }^{1}$
}

\author{
${ }^{1}$ Third Medical Department, First Faculty of Medicine and General Teaching Hospital, Charles \\ University, Prague, Czech Republic and ${ }^{2}$ Novartis International AG, Basel, Switzerland
}

Received October 3, 2006

Accepted August 1, 2007

On-line January 17, 2008

\section{Summary}

Lipoprotein(a) $[\mathrm{Lp}(\mathrm{a})]$ comprises of an LDL particle and apolipoprotein(a) [apo(a)] and its elevated levels are considered a risk factor for atherosclerosis. The aim of our study was to find out whether elevated $\mathrm{Lp}(\mathrm{a})$ levels are associated with increased risk of atherosclerosis in patients with multiple other risk factors. We further tested the association of three polymorphisms of the apo(a) gene promoter with $L p(a)$ levels. No significant correlation was detected between $L p(a)$ levels and lipid and clinical parameters tested. The study demonstrated a significantly $(p=0.0219)$ elevated $\mathrm{L} p(\mathrm{a})$ level (mean $28 \pm 35 \mathrm{mg} / \mathrm{dl}$, median 0.14 ) in patients with coronary heart disease (CHD). In a group with premature $\mathrm{CHD}$ the correlation was not significant anymore. There was a significant correlation between polymorphic loci of the promoter region of apo(a) gene and $L p(a)$ levels $(+93 \mathrm{C}>T$, $p=0.0166$, STR, $p<0.0001$ ). Our study suggests that elevated $\mathrm{L} p(\mathrm{a})$ level is an independent risk factor of $\mathrm{CHD}$ in carriers of other important $\mathrm{CHD}$ risk factors. Observed association of sequence variants of the promoter of apo(a) gene with $L p(a)$ levels is caused in part due to linkage to a restricted range of apo(a) gene length isoforms.

\section{Key words}

Lipoprotein(a) • Apolipoprotein(a) • Atherosclerosis • Risk factors

- Coronary heart disease $\bullet$ Gene polymorphisms

\section{Corresponding author}

Lukáš Zlatohlávek, $3^{\text {rd }}$ Medical Department, $1^{\text {st }}$ Faculty of Medicine and General Teaching Hospital, Charles University in Prague, U Nemocnice 1, 128 00, Prague 2, Czech Republic. E-mail: I.zlato@tiscali.cz

\section{Introduction}

Lipoprotein(a) $[\mathrm{Lp}(\mathrm{a})]$ comprises of an LDL (low-density lipoprotein) particle covalently bound to a specific glycoprotein, apolipoprotein(a) [apo(a)], by apoB-100 (Hořejší and Češka 2000). Apolipoprotein(a) determines the structural and functional properties of the lipoprotein. A number of prospective and retrospective studies demonstrated that increased levels of $L p(a)$ are associated with atherosclerosis and $\operatorname{Lp}(\mathrm{a})$ is therefore considered an independent risk factor of atherosclerosis (Berglund and Ramakrishnan, 2004, Evans et al. 2001, Marcovina and Koschinsky, 2002). In numerous trials, patients with $\mathrm{Lp}$ (a) levels above $30 \mathrm{mg} / \mathrm{dl}$ had markedly increased risk of coronary heart disease (Foody et al. 2000, Paultre et al. 2000) and a susceptibility to occlusive complications after various interventions (percutaneous transluminal coronary angioplasty, stent placement) (Rifai et al. 2004).

Several mechanisms linking $\mathrm{Lp}(\mathrm{a})$ and development of atherosclerosis have been proposed. In arterial intima, $L p(a)$ is located only in atherosclerotic plaques but not in the intact tissue. $\mathrm{Lp}$ (a) captured in the atherosclerotic plaque stimulates smooth muscle cells proliferation and its binding to extracellular matrix enhances lipid accumulation. As a non-functional structural homologue of plasminogen it can also negatively affect the process of fibrinolysis (Koschinsky and Marcovina 2004, Shai et al. 2005a).

Plasma Lp(a) concentration is predominantly determined by genetic factors and is not affected by diet (Boerwinkle et al. 1992). Certain drugs (nicotinic acid 
and its analogues) and sexual hormones (androgens, estrogens, progesterone) have a lowering effect on $\mathrm{Lp}(\mathrm{a})$ levels (Šulcová et al. 2001). No effects of statins and fibrates on the $\mathrm{Lp}$ (a) were demonstrated (Lippi and Guidi, 2003).

The amount of synthesized apo(a) is considerably different among individuals in a population. There is an apo(a) gene length polymorphism that accounts for about 40-60\% of the variance (Cohen et al. 1993, Kraft et al. 1992). Part of the variance could be attributed to polymorphic sites either in the coding sequence or in the transcription regulatory sequences of apo(a) gene. Four polymorphisms with possible relation to $\mathrm{Lp}(\mathrm{a})$ levels have been identified in the promoter region of the apo(a) gene. These are three single nucleotide substitutions $(+121 \mathrm{G}>\mathrm{A},+93 \mathrm{C}>\mathrm{T}$, and $-772 \mathrm{G}>\mathrm{A}$ ) and one pentanucleotide TTTTA repetition (7-11 repeats) designated as the STR (short tandem repeat) locus (Trommsdorf et al. 1995, Zysow et al. 1995). In contrast to the other polymorphic sites the $-772 \mathrm{G}>$ A substitution was not reported to be functional.

The aim of our study was to test if Lp(a) levels are associated with coronary heart disease and premature manifestation of coronary atherosclerosis in patients with other important risk factors of atherosclerosis. We analyzed the relationship between $\mathrm{Lp}$ (a) levels and serum lipids (total cholesterol, LDL-cholesterol, HDL-cholesterol, triglycerides, apoB-100) and other risk factors of atherosclerosis (type 2 diabetes mellitus, arterial hypertension, smoking, and overweight). Finally, we investigated an association between selected polymorphic sites in the apo(a) gene promoter region and Lp(a) plasma levels.

\section{Methods}

\section{Subjects}

3915 out-patients followed at the Centre of Preventive Cardiology of the General Teaching Hospital, Charles University in Prague with dyslipidemia and other CHD risk factors (e.g. type 2 diabetes mellitus, hypertension, overweight, metabolic syndrome) were included in the study. Characteristics of the study group are shown in Table 1.

The study group was divided into quintiles according to $\mathrm{Lp}(\mathrm{a})$ level. We randomly selected a representative subgroup of 650 individuals (each sixth patient from each quintile). One hundred patients with inflammatory diseases, malignancies, renal insufficiency or other diseases, which could affect the Lp(a) level, were excluded. The presence of type 2 diabetes mellitus, hypertension, smoking, overweight [defined as BMI (body mass index) over 25] and of CHD (defined as a documented myocardial infarction, revascularization procedure, angina, positive stress test or positive coronary angiography) were recorded in the final group of 550 individuals. The final group did not differ from the principal group in lipid parameters and it included $12.8 \%$ of patients with type 2 diabetes mellitus, $35.4 \%$ of patients with arterial hypertension, $26.5 \%$ of smokers, $12.7 \%$ patients with documented CHD and $7.8 \%$ patient with premature CHD (men $<55$ years of age, women $<65$ years of age). When subgroups of diabetics and non-diabetics, hypertonics and non-hypertonics, smokers and non-smokers, males and females and those with CHD and without CHD were mutually compared, no significant differences were observed in selected lipid and clinical parameters (including age). The study was approved by the ethics committee of the General Teaching Hospital in Prague and all study participants gave their informed consent.

\section{Biochemical analysis}

Venous blood was collected after $12 \mathrm{~h}$ fasting and $\mathrm{Lp}(\mathrm{a})$ concentrations were measured using frozen serum $\left(-20{ }^{\circ} \mathrm{C}\right)$, separated within two hours after blood collection, by the immuno LEIA $^{\circledR}$ Lp(a) method (Technoclone GmbH, Vienna, Austria). We used internal control samples as well as control samples and standards provided by the manufacturer during each assay.

Plasma concentrations of total cholesterol, HDL [high-density lipoprotein] cholesterol, triglycerides, and apo-B were determined on automatic analyzers (Modular SWA, Roche). LDL cholesterol level was calculated by Friedewald equation (LDL-c $=\mathrm{TC}-\mathrm{HDL}-\mathrm{c}-\mathrm{TG} / 2.2$ ).

\section{DNA analysis}

DNA was isolated from fresh or frozen whole blood using a salting-out method according to Miller et al. (1988). Subjects were then directly genotyped for $+121 \mathrm{G}>\mathrm{A}$, +93 $\mathrm{C}>\mathrm{T}$, and $-772 \mathrm{G}>\mathrm{A}$ apo(a) gene polymorphisms. The sequence of the proximal promoter and the pentanucleotide microsatellite (STR locus) from the distal promoter were amplified using primers described in our previous study (Zídková et al. 2007). The promoter fragment was then restricted in two separated $10 \mu \mathrm{l}$ reaction mixtures using 5 units of the Hpy188III (New England Biolabs GmbH, Frankfurt am 
Table 1. Clinical and lipid characteristics of the principal out-patient group, serum lipid parameters and Pearson correlation coefficients to $\operatorname{Lp}(\mathrm{a})$.

\begin{tabular}{lcccccc}
\hline Characteristics & N & Mean \pm SD & Median & Minimum & Maximum $^{\text {Pearson }^{+}}$ \\
\hline Age (years) & 3915 & $50.95 \pm 16.34$ & 53.00 & 19 & 94 & 0.14131 \\
Total cholesterol (mmol/l) & 3869 & $6.66 \pm 2.30$ & 6.50 & 2.77 & 37.63 & 0.06036 \\
LDL cholesterol (mmol/l) & 3241 & $4.19 \pm 1.64$ & 4.01 & 0.56 & 18.80 & 0.13002 \\
HDL cholesterol (mmol/l) & 3644 & $1.39 \pm 0.44$ & 1.35 & 0.10 & 4.04 & 0.07100 \\
Triglycerides $(\mathrm{mmol} / \mathrm{l})$ & 3863 & $2.85 \pm 4.71$ & 1.80 & 0.15 & 88.35 & -0.08923 \\
Apo-B $(\mathrm{mmol} / \mathrm{l})$ & 3838 & $1.28 \pm 0.44$ & 1.24 & 0.18 & 5.52 & 0.12770 \\
Lp $(\mathrm{a})(\mathrm{mg} / \mathrm{dl})$ & 3915 & $28 \pm 35$ & 14 & 0.00 & 410 & - \\
\hline
\end{tabular}

$\mathrm{N}$ - number of individuals with available data, ${ }^{+}$value of Pearson correlation coefficient $(r)$ to $L p(a), r$ value of 0.3 was considered as significant

Table 2. Clinical and lipid characteristics of the final group, serum lipid parameters and Pearson correlation coefficients to $L p(a)$.

\begin{tabular}{|c|c|c|c|c|c|c|}
\hline Characteristics & $\mathbf{N}$ & Mean \pm SD & Median & Minimum & Maximum & Pearson $^{+}$ \\
\hline Age (years) & 550 & $49.56 \pm 12.54$ & 51.50 & 30 & 81 & 0.15007 \\
\hline Diabetes mellitus & 70 & - & - & - & - & - \\
\hline Arterial hypertension & 195 & - & - & - & - & - \\
\hline Smoking & 146 & - & - & - & - & - \\
\hline Overweight $(B M I>25)$ & 215 & - & - & - & - & - \\
\hline CHD & 70 & - & - & - & - & - \\
\hline Premature $C H D$ & 78 & - & - & - & - & - \\
\hline Total cholesterol $(\mathrm{mmol} / \mathrm{l})$ & 550 & $6.44 \pm 1.94$ & 5.90 & 3.04 & 20.78 & 0.05542 \\
\hline LDL cholesterol (mmol/l) & 550 & $4.35 \pm 1.82$ & 4.12 & 0.62 & 9.60 & 0.12788 \\
\hline HDL cholesterol (mmol/l) & 550 & $1.30 \pm 0.37$ & 1.33 & 0.40 & 3.12 & 0.1050 \\
\hline Triglycerides (mmol/l) & 550 & $2.52 \pm 5.01$ & 1.95 & 0.45 & 45.35 & -0.09024 \\
\hline apo-B (mmol/l) & 550 & $1.29 \pm 0.34$ & 1.25 & 0.19 & 5.48 & 0.13040 \\
\hline$L p(a)(m g / d l)$ & 550 & $27 \pm 56$ & 13.5 & 0.00 & 340 & - \\
\hline
\end{tabular}

$\mathrm{N}$ - number of individuals with available data, ${ }^{+}$value of Pearson correlation coefficient $(r)$ to $L p(a), r$ value of 0.3 was considered as significant

Main, Germany) enzyme for the $+121 \mathrm{G}>\mathrm{A}$ variant detection and 5 units of the HpyCH4IV (NEB) enzyme for the $+93 \mathrm{C}>\mathrm{T}$ variant detection. Restricted fragments were then subjected to $2 \%$ agarose gel electrophoresis and visualized in UV light after ethidium bromide staining. The STR locus product varied in size according to the number of TTTTA repeat units from $164 \mathrm{bp}$ (7 repeats) to $184 \mathrm{bp}$ (11 repeats) and was measured by fragmentation analysis conducted on ABI PRISM 310 Genetic Analyzer (Applied Biosystems, Foster City, CA, USA).

\section{Statistical analysis}

Correlation between $\mathrm{Lp}(\mathrm{a})$ levels and serum lipid concentrations, apo-B plasma levels, risk factors of atherosclerosis, and prevalence of CHD was evaluated using Pearson's correlation coefficient (r). The Lp(a) plasma levels in subgroups of diabetics and non-diabetics, hypertonics and non-hypertonics, smokers and non-smokers, and those with heart disease and without heart disease were compared by Mann-Whitney test. The logistic regression analysis was used to establish predicted probability. The ANOVA test was employed to reveal an association of polymorphic loci with $\mathrm{Lp}(\mathrm{a})$ levels. Each polymorphic locus was tested for significant deviation from Hardy-Weinberg equilibrium using the $\chi^{2}$ test $(\mathrm{p}<0.05,1$ d.f.). 


\section{Results}

No significant correlation was observed between Lp(a) levels and serum lipids and age in the overall patient group of 3915 individuals (for relevant values of Pearson's correlation coefficient see Table 1). The same correlation analyses were conducted in the final group of 550 individuals (Table 2), which had correlation coefficients not markedly different from those in the basic group (data not shown).

When we compared the mean Lp(a) plasma levels between the subgroup of type 2 diabetics and non-diabetics $(p=0.3935)$, hypertonics and nonhypertonics $(\mathrm{p}=0.2329)$, and smokers and non-smokers ( $p=0.2682)$, no significant differences were detected.

We found a significant increase of mean $\mathrm{Lp}(\mathrm{a})$ levels in the subgroup of patients with CHD ( $p=0.0219)$. In the logistic regression analysis we utilized the $\mathrm{Lp}(\mathrm{a})$ plasma level as a predictor of CHD. Lipoprotein(a) levels significantly affected the probability of CHD ( $p=0.0234)$. The predicted probability represents the likelihood of CHD development among patients with a given $\mathrm{Lp}(\mathrm{a})$ level (Fig. 1). When we analyzed the individuals with premature manifestation of CHD (78 individuals) the association of $\mathrm{Lp}$ (a) levels with the development of CHD was not significant $(\mathrm{p}=0.1471)$.

Allelic frequencies of the two single nucleotide substitutions were as follows: $+121 \mathrm{G}>\mathrm{A}(0.794 / 0.206 \pm$ $0.017),+93 \mathrm{C}>\mathrm{T}(0.865 / 0.135 \pm 0.010)$. Genotypes and relevant mean $\mathrm{Lp}$ (a) levels are summarized in Table 3. The most frequent allele of the STR locus had 8 repeats $(0.711 \pm 0.019)$, allelic frequencies of other alleles were: STR with 7 repeats $(0.008 \pm 0.003)$, STR with 9 repeats $(0.151 \pm 0.015)$, STR with 10 repeats $(0.111 \pm 0.013)$, and STR with 11 repeats $(0.019 \pm 0.006)$. All genotypes detected in the final group and related Lp(a) levels are given in Table 4. Distribution of the genotype frequencies were in Hardy-Weinberg equilibrium.

No effect of the $+121 \mathrm{G}>\mathrm{A}$ polymorphism on $\mathrm{L} p$ (a) level was observed $(\mathrm{p}=0.2515)$, but there was a significant association of the $+93 \mathrm{C}>\mathrm{T}$ polymorphism with Lp(a) levels $(p=0.0166)$. There was a highly significant association of different length of the STR locus with Lp(a) levels $(p<0.0001)$. Our results indicate that mean $\mathrm{Lp}$ (a) levels increase with a decreasing number of TTTTA repeats. Moreover, when we analyzed a combined effect of all three polymorphic sites on $\mathrm{Lp}(\mathrm{a})$ levels the association of the $+93 \mathrm{C}>\mathrm{T}$ polymorphism became attenuated and was no more significant

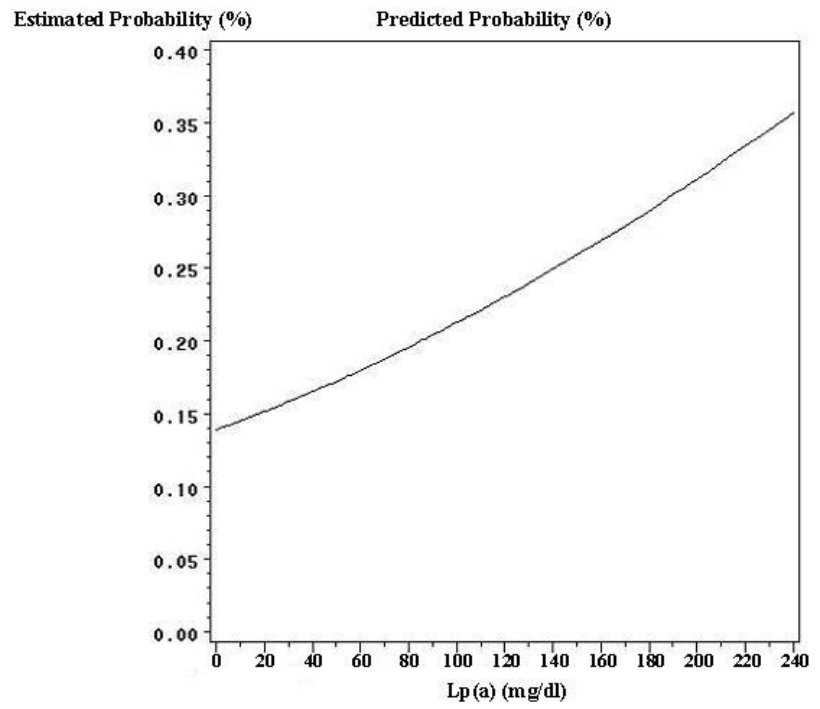

Fig. 1. The predicted probability represents likelihood of coronary heart disease development among patients with a given Lp(a) level.

( $p=0.6001)$, whereas the effect of the STR locus was still persistent $(\mathrm{p}=0.0029)$.

\section{Discussion}

The study was carried out in a group of patients of the Centre of Preventive Cardiology and thus it includes individuals with different risk factors of atherosclerosis. The purpose of the study was to find out whether Lp(a) levels are still associated with CHD in patients with other cardiovascular risk factors (type 2 diabetes, arterial hypertension, smoking, obesity) and if $\mathrm{Lp}$ (a) levels are independent of these risk factors. We also tested the association of three polymorphic loci from the apo(a) gene promoter region with Lp(a) levels. The polymorphic sites were chosen for the analysis based on the data from previous studies (Brazier et al. 1999, Kalina et al. 2001).

No correlation was detected between $\mathrm{Lp}(\mathrm{a})$ levels and risk factors of atherosclerosis examined. Our results are in agreement with other studies (Shai et al. $2005 \mathrm{~b}$ ), but in other studies is demonstrated a positive correlation of $\mathrm{Lp}(\mathrm{a})$ and diabetes mellitus. Major limitation of this study is that it included patients with renal complications (albuminuria and renal insufficiency), which increase Lp(a) levels. Thus we support the independent role of $\mathrm{Lp}(\mathrm{a})$ on studied risk factors of atherosclerosis.

In our study there is a lack of dependence of $\mathrm{Lp}$ (a) levels and apo-B, which forms a part of $\mathrm{Lp}(\mathrm{a})$, but 
Table 3. Number of observed genotypes, mean $L p(a)$ plasma levels and standard deviation (SD) for the $+121 G>A$ and $+93 C>T$ polymorphic sites from the apo(a) gene promoter region in quintile based group.

\begin{tabular}{|c|c|c|c|c|c|}
\hline \multirow[t]{2}{*}{ Genotypes } & & \multirow[b]{2}{*}{$\mathbf{N}$} & \multicolumn{3}{|c|}{ Lipoprotein(a) (mg/dl) } \\
\hline & & & Mean \pm SD & Minimum* & Maximum \\
\hline \multirow[t]{3}{*}{+121} & $G / G$ & 348 & $39 \pm 37$ & 0.0 & 205 \\
\hline & $G / A$ & 177 & $45 \pm 46$ & 0.0 & 190 \\
\hline & $A / A$ & 25 & $54 \pm 66$ & 0.0 & 268 \\
\hline \multirow[t]{3}{*}{+93} & $C / C$ & 412 & $44 \pm 43$ & 0.0 & 268 \\
\hline & $C / T$ & 128 & $34 \pm 36$ & 0.0 & 131 \\
\hline & $T / T$ & 10 & $19 \pm 18$ & 0.0 & 50 \\
\hline
\end{tabular}

* the lowest non-zero detected $\mathrm{Lp}(\mathrm{a})$ level was $1 \mathrm{mg} / \mathrm{dl}$

Table 4. Number of observed genotypes, mean $L p(a)$ plasma levels ( \pm SD) for the STR polymorphic site from the apo(a) gene promoter region in quintile based group.

\begin{tabular}{lcccc}
\hline $\begin{array}{l}\text { Genotype } \\
\text { Number of TTTTA repetition }\end{array}$ & $\mathbf{N}$ & Mean \pm SD & $\begin{array}{c}\text { Lipoprotein(a) (mg/dl) } \\
\text { Minimum* }\end{array}$ & Maximum \\
\hline $7 / 10 ; 7 / 8$ & 9 & $76 \pm 47$ & 5.0 & 143 \\
$8 / 8$ & 282 & $44 \pm 43$ & 0.0 & 268 \\
$8 / 9$ & 115 & $38 \pm 38$ & 0.0 & 131 \\
$8 / 10$ & 82 & $43 \pm 40$ & 0.0 & 160 \\
$8 / 11$ & 13 & $27 \pm 28$ & 0.0 & 81 \\
$9 / 9$ & 16 & $23 \pm 35$ & 0.0 & 132 \\
$9 / 10 ; 9 / 11$ & 19 & $23 \pm 19$ & 0.0 & 67 \\
$10 / 10 ; 10 / 11 ; 11 / 11$ & 14 & $10 \pm 7$ & 0.0 & 22 \\
\hline
\end{tabular}

* the lowest non-zero detected $\mathrm{Lp}(\mathrm{a})$ level was $1 \mathrm{mg} / \mathrm{dl}$

such correlation was also missing in other trials (Lippi and Guidi 2003). In most individuals, the Lp(a) concentration is very low in comparison with the abundance of other lipoproteins containing apo-B. It seems that even markedly decreased apo-B plasma levels are still not limiting for the rate of $\mathrm{Lp}$ (a) synthesis

Significantly increased mean Lp(a) level (mean $0.49 \pm 0.54 \mathrm{mg} / \mathrm{dl}$ ) was found in a subgroup of patients suffering from CHD. However, such significant correlation was absent when only patients with premature CHD were included. An insufficient sample size of the subgroup with premature CHD could be the possible reason for our results, because a possitive correlation was demonstrated in other trials (Stein and Rosenson 1997, Berlung and Ramakrishnan 2004). Nevertheless, our results support the notion that increased $\mathrm{Lp}$ (a) levels are associated with CHD in patients having other CHD risk factors.
Gene variants affecting apo(a) gene transcription may contribute to the high variability of $\mathrm{Lp}$ (a) plasma concentrations. Suzuki et al. (1997) reported a potentially positive role of the $+121 \mathrm{G}>\mathrm{A}$ substitution on apo(a) gene transcription, but this was not reproduced by $\mathrm{Wu}$ and Lee (2003). We did not detect any association of the +121 $\mathrm{G}>\mathrm{A}$ polymorphism with $\mathrm{Lp}(\mathrm{a})$ levels. A significant association of the $+93 \mathrm{C}>\mathrm{T}$ polymorphism with $\mathrm{Lp}(\mathrm{a})$ levels is in accordance with its direct negative effect on apo(a) production (Zysow et al. 1995). Nevertheless, in Caucasians the effect is usually masked by the strong linkage disequilibrium with intermediate apo(a) gene length isoforms (Brazier et al. 1999).

Several studies have reported a correlation between the STR locus of apo(a) gene promoter and plasma Lp(a) concentrations (Brazier et al. 1999, Kalina et al. 2001). The correlation was independent of apo(a) size isoforms and it accounted for up to $14 \%$ of $\mathrm{Lp}$ (a) 
level variation (Brazier et al. 1999, Trommsdorff et al. 1995). Our findings are consistent with these data. It is supposed to be due to the linkage disequilibrium of different STR alleles to the distinct range of apo(a) isoforms and to other functional changes influencing apo(a) production rate. The STR allele with 9 repeats was reported to be in a linkage disequilibrium with the $+93 \mathrm{~T}$ promoter variant (Holmer et al. 2003) and with apo(a) middle-sized isoforms (Puckey et al. 1997). It seems that the association of $+93 \mathrm{C}>\mathrm{T}$ polymorphism with $\mathrm{Lp}(\mathrm{a})$ levels was actually caused by the STR allele with 9 repeats at least in part due to the linkage with restricted apo(a) gene length isoforms. Such a conclusion is in agreement with results of the combined analysis where the effect of $+93 \mathrm{C}>\mathrm{T}$ polymorphism lost its significance and the effect of the STR locus was preserved. Thus, our results are in compliance with previously published data (Kraft et al. 1998, Puckey et al. 1997).

Our study suggests that elevated Lp(a) level is independently associated with CHD in patients with other important risk factors of atherosclerosis. Sequence variants of the regulatory regions of apo(a) gene are associated with $\mathrm{Lp}$ (a) plasma levels, in particular due to the linkage to a restricted range of apo(a) gene length isoforms.

\section{Conflict of Interest}

There is no conflict of interest.

\section{Acknowledgements}

This work was supported by grant NR/9411-3 and research project MSM 0021620807.

\section{References}

BERGLUND L, RAMAKRISHNAN R: Lipoprotein(a): an elusive cardiovascular risk. Arterioscler Thromb Vasc Biol 24: 2219-2226, 2004.

BOERWINKLE E, LEFFERT CC, LIN J, LACKNER C, CHIESA G, HOBBS HH: Apolipoprotein(a) gene accounts for greater than $90 \%$ of the variation in plasma lipoprotein(a) concentrations. J Clin Invest 90: 52-60, 1992.

BRAZIER L, TIRET L, LUC G, ARVEILER D, RUIDAVETS JB, EVANS A, CHAPMAN J, CAMBIEN F, THILLET $\mathrm{J}$ : Sequence polymorphisms in the apolipoprotein(a) gene and their association with lipoprotein(a) levels and myocardial infarction. The ECTIM study. Atherosclerosis 144: 323-333, 1999.

COHEN JC, CHIESA G, HOBBS HH: Sequence polymorphisms in the apolipoprotein(a) gene - evidence for dissociation between apolipoprotein(a) size and plasma lipoprotein(a) levels. J Clin Invest 91: 1630-1636, 1993.

EVANS RW, SHPILBERG O, SHATEN BJ, ALI S, KAMBOH MI, KULLER LH: Prospective association of lipoprotein(a) concentrations and apo(a) size with coronary heart disease among men in the Multiple Risk Factor Intervention Trial. J Clin Epidemiol 54: 51-57, 2001.

FOODY JM., MILBERG JA, PEARCE GL, SPRECHER DL: Lipoprotein(a) associated with coronary artery disease in older women: age and gender analysis. Atherosclerosis 153: 445-451, 2000.

HOLMER SR, HENGSTENBERG C, KRAFT HG, MAYER B, POLL M, KURZINGER S, FISCHER M, LOWEL H, KLEIN G, RIEGGER GA, SCHUNKERT H: Association of polymorphisms of the apolipoprotein(a) gene with lipoprotein(a) levels and myocardial infarction. Circulation 107: 696-701, 2003.

HOŘEJŠÍ B, ČEŠKA R: Apolipoproteins and atherosclerosis. Apolipoprotein E and apolipoprotein(a) as candidate genes of premature development of atherosclerosis. Physiol Res 49 (Suppl 1): S63-S69, 2000.

KALINA Á, CSÁSZÁR A, FUST G, NAGY B, SZALAI C, KARÁDI I, DUBA J, PROHÁSZKA Z, HORVÁTH L, DIEPLINGER H: The association of serum lipoprotein(a) levels, apolipoprotein(a) size and (TTTTA) polymorphism with coronary heart disease. Clin Chima Acta 309: 45-51, 2001.

KRAFT HG, KOCHL S, MENZEL HJ, SANDHOLZNER C, UTERMANN G: The apolipoprotein(a) gene: a transcribed hypervariable locus controlling plasma lipoprotein(a) concentration. Hum Genet 90: 220-230, 1992.

KRAFT HG, WINDEGGER M., MENZEL HJ, UTERMANN G: Significant impact of the +93 C/T polymorphism in the apolipoprotein(a) gene on $\mathrm{Lp}$ (a) concentrations in Africans but not in Caucasians: confounding effect of linkage disequilibrium. Hum Mol Genet 7: 257-264, 1998. 
KOSCHINSKY ML, MARCOVINA SM: Structure-function relationships in apolipoprotein(a): insights into lipoprotein(a) assembly and pathogenicity. Curr Opin in Lipidol 15: 167-174, 2004.

LIPPI G, GUIDI G: Lipoprotein(a): an emerging cardiovascular risk factor. Crit Rev Clin Lab Sci 40: 1-42, 2003.

MARCOVINA SM, KOSCHINSKY M: A critical evaluation of the role of Lp(a) in cardiovascular disease: can Lp(a) be useful in risk assessment? Semin Vasc Med 2: 335-344, 2002.

MILLER SA, DYKES DD, POLESKY HF: A simple salting out procedure for DNA extraction from human nucleated cells. Nucl Acid Res 16: 1215, 1988.

PAULTRE F, PEARSON TA, WEIL HF, TUCK CH, MYERSON M, RUBIN J, FRANCIS CK, MARX HF, PHILBIN EF, REED RG, BERGLUND L: High levels of Lp(a) with a small apo(a) isoform are associated with coronary artery disease in African American and white men. Arterioscler Thromb Vasc Biol 20: 2619-2624, 2000.

PUCKEY LH, LAWN RM, KNIGHT BL: Polymorphisms in the apolipoprotein(a) gene and their relationship to allele size and plasma lipoprotein(a) concentration. Hum Mol Genet 6: 1099-1107, 1997.

RIFAI N, MA J, SACKS FM, RIDKER PM, HERNANDEZ WJ, STAMPFER MJ, MARCOVINA SM: Apolipoprotein(a) size and lipoprotein(a) concentration and future risk of angina pectoris with evidence of severe coronary atherosclerosis in men: Physicians Health Study. Clin Chem 50: 1364-1371, 2004.

SHAI I, RIMM EB, HANKINSON SE, CANNUSCIO C, CURAHN G, MANSON JE, RIFAI N, STAMPFER MJ, MA $\mathrm{J}$ : Lipoprotein(a) and coronary heart disease among women: beyond a cholesterol carrier? Eur Heart J 26: 1633-1639, 2005a.

SHAI I, SCHULZE MB, MANSON JE, STAMPFER MJ, RIFAI N, HU FB: A prospective study of lipoprotein(a) and risk of coronary heart disease among women with type 2 diabetes. Diabetologia 48: 2691-2692, 2005 b.

SUZUKI K, KURIYAMA M, SAITO T, ICHINOSE A: Plasma lipoprotein(a) levels and expression of the apolipoprotein(a) gene are dependent on the nucleotide polymorphisms in its 5'-flanking region. J Clin Invest 99: 1361-1366, 1997.

STEIN JH, ROSENSON RS: Lipoprotein Lp(a) excess and coronary heart disease. Arch Intern Med 157: 1170-1176, 1997.

ŠULCOVÁ J, HILL M, MAŠEK Z, ČEŠKA R, NOVÁČEK A, HAMPL R, STÁRKA L: Effects of transdermal application of 7-oxo-DHEA on the levels of steroid hormones, gonadotropins and lipids in healthy men. Physiol Res 50: 9-18, 2001.

TROMMSDORFF M, KOCHL S, LINGENHEL A, KRONENBERG F, DELPORT R, VERMAAK H, LEMMING L, KLAUSEN IC, FAERGEMAN O, UTERMANN G: A pentanucleotide repeat polymorphism in the 5' control region of the apolipoprotein(a) gene is associated with lipoprotein(a) plasma concentration in Caucasians. J Clin Invest 96: 150-157, 1995.

WU JH, LEE IN: Studies of apolipoprotein(a) promoter from subjects with different plasma lipoprotein(a) concentrations. Clin Biochem 36: 241-246, 2003.

ZÍDKOVÁ K, KEBRDLOVÁ V, ZLATOHLÁVEK L, ČEŠKA R: Detection of variability in apo(a) gene transcription regulatory sequences using the DGGE method. Clin Chim Acta 376: 77-81, 2007.

ZYSOW BR, LINDAHL GE, WADE DP, Knight BL, LAWN RM: C/T polymorphism in the 5' untranslated region of the apolipoprotein(a) gene introduces an upstream ATG and reduces in vitro translation. Arterioscler Thromb Vasc Biol 15: 58-64, 1995. 